Article

\title{
Project-Based Teaching of the Topic "Energy Sources" in Physics Via Integrated e-Learning-Pedagogical Research in the 9th Grade at Two Primary Schools in Slovakia
}

\author{
Žaneta Gerhátová, Peter Perichta and Marián Palcut* *(1)
}

Faculty of Materials Science and Technology in Trnava, Slovak University of Technology in Bratislava, J. Bottu 25, 91724 Trnava, Slovakia; zaneta.gerhatova@stuba.sk (Ž.G.); peter.perichta@gmail.com (P.P.)

* Correspondence: marian.palcut@stuba.sk

Received: 12 November 2020; Accepted: 4 December 2020; Published: 8 December 2020

check for updates

\begin{abstract}
This work presents the results of two-year-long pedagogical research, the aim of which was to demonstrate the applicability of the usage of a new strategy in education-Integrated e-Learning (INTe-L) - through its introduction into project-based physics teaching in Slovakia. The INTe-L strategy is built around the role of experiments and interactive simulations in knowledge acquisition and on the possibility of integrating scientific methods in education. The elements of INTe-L are the following: (a) real on-site and real remote experiments, (b) interactive virtual experiments (e-simulations) and (c) educational e-materials. The primary objective of our study was to determine the suitability of project-based teaching with INTe-L elements for the topic "Energy Sources". The research was based on the following hypothesis: project-based teaching via INTe-L of the topic "Energy Sources" in physics is more effective than the traditional (instructionist) way of teaching. To verify the hypothesis, we performed a pedagogical experiment on a sample of 155 respondents in the 9th grade at two primary schools in Slovakia. The pupils were divided into two working groups: an experimental group (EG) of 85 pupils and a control group (CG) of 70 pupils. The pupils with worse grades were included in the EG. To get relevant feedback, pre-test and post-test studies and an interview were developed and applied. The results attained in both groups were statistically processed, evaluated and subsequently compared. A two-phase test with dispersion equality proved that differences in the pre-test scores in the EG and CG were not statistically significant. The differences in the final didactic test (post-test) results achieved by the EG and CG, on the other hand, were statistically significant and better scores in the EG were obtained. A positive change of pupils' attitude in the EG towards physics after the execution of our project-based teaching was noted. The evaluation of the results attained by the pupils proved that the introduction of project-based teaching via INTe-L was an effective strategy to improve Physics teaching. As such, the implementation of this interactive strategy into the instructional education process at primary schools is recommended.
\end{abstract}

Keywords: energy sources; experiments; physics education; integrated e-learning; project-based teaching

\section{Introduction}

Physics is a science that plays a fundamental role in most natural phenomena observed around us [1]. Physical laws are not only encountered in nature itself, but also in the operation of machinery and equipment. Despite its significance, Slovak pupils are underperforming in this subject. The Program for International Student Assessment of the Organization for Economic Co-operation and Development (PISA OECD) [2] tested the mathematical and reading literacy of 15-year-old primary school pupils along with their literacy in natural sciences. The results for scientific literacy are presented in Figure 1 [2]. 
The testing was last conducted in 2018. The average score of Slovak pupils achieved in 2012, 2015 and 2018 was significantly below the OECD average. In response to this underperformance, we asked the following questions: "How can we teach physics with better results? How can we make pupils of this subject more interested in, entertained and attracted by it?" The task of physics teaching is not to pass on a certain amount of knowledge to pupils but to prepare them for planned work, independent knowledge acquisition and problem solving [3]. As such, the transformation of physics education is essential [4]. The process of teaching physics and other science subjects should reflect as closely as possible what is being done in real science [5]. The fundamental element of science is the experiment. Integrated e-Learning (INTe-L) is a new generation of e-learning that complements standard e-learning with experiments [6]. The basic elements of the INTe-L strategy are real on-site or remote experiments via the Internet, virtual e-simulations and e-learning materials providing the necessary curriculum and theoretical basis for comprehending and quantifying the phenomenon [7-10]. Currently, a very popular representative of the inductive method is Inquiry-based Learning (IBL [11,12]). It applies to pupils' activities in which they develop their awareness and knowledge of scientific concepts. In our opinion, the methods of scientific learning should already be applied at the primary level.

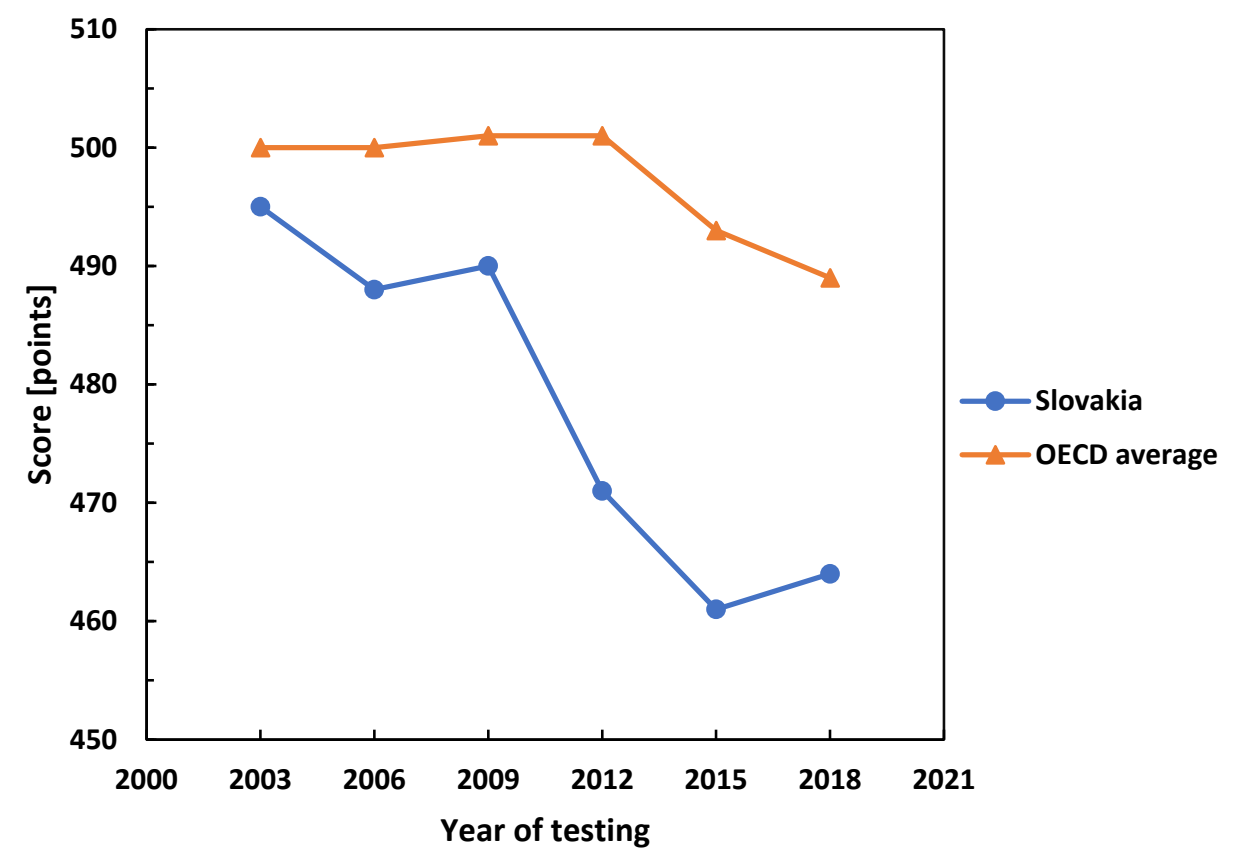

Figure 1. Scores of Slovak pupils in scientific literacy according to the Program for International Student Assessment of the Organization for Economic Co-operation and Development (PISA OECD) [2].

Project-based learning (PBL) is a student-centered form of learning [13]. It is built on three constructivist principles: it is context-specific, pupils are actively involved in the process and their goals are achieved via social interactions and knowledge sharing. It is a type of IBL where the learning context is driven through authentic encounters with real-world problems [14]. It leads to purposeful learning experiences [15]. During their project engagements, students work as a team. They face problems which need to be tackled in order to reach a reasonable conclusion and present a concrete end product at the end of the activity. According to [16], there are five characteristic features of projects: centrality, autonomy, realism, a driving question and constructive investigation. The unique feature of PBL is the production of a concrete end product, a "concrete artefact" [17]. The product is in the form of videos, images, photographs, reports, models or other forms of documentation [18]. PBL is a self-regulated learning process that promotes pupils' conceptual knowledge acquisition through a systematic process of documenting, presenting and reflecting on learning [19]. Furthermore, students develop their 
collaboration skills through clear goal setting, planning and organization. The students also experience an element of choice and proceed with learning at their own speed and on an individual basis [20].

\section{Background}

The education of children at primary schools has a rich history. Educational strategy has traditionally been based on the theories of childhood, i.e., understandings about children and their mental development [21]. Early approaches to modern education reflected 19th century Victorian thoughts about children [22]. The child was regarded as an indolent and undisciplined being that needs firm instruction and constant physical and mental training. Such attitudes towards children led to a development of vertical teacher-student relationships where teachers serve as narrators and students are patient, listening objects. In the current context, the term instructionism is used to describe teacher-controlled, teacher-driven, highly structured and non-interactive instructional practices [23]. Instructionism is also regarded as systematic and explicit teaching that emphasizes teacher behavior. While teachers play the role of instructors, students are regarded as passive receptors of knowledge [23]. The teacher provides the instructions and pupils are expected to obey them. Autocratic management of the classroom constitutes the basis of instructional teaching and management tasks. It is highly task-oriented, goal-driven and over-emphasizes the teacher's importance in education [24]. Autocratic management, although debated by some authors [21], can be used to control discipline in the classroom.

As opposed to instructionism, constructivism has seen a rise in popularity in recent years $[25,26]$. In current praxis, constructivism as a professional term is used to describe individual, student-centered, loosely structured, process-driven and highly interactive education practices. Constructivism describes the learning process as active knowledge acquisition and not as passive knowledge assimilation [23]. In the instructionist classroom, knowledge has the status of final and absolute certainty. The world is regarded as dualistic: the body is subordinate to mind and subjectivity is outmatched by objective reality [21]. The teacher is a symbol of authority, control and order [21]. On the other hand, a holistic worldview is characteristic for constructivism. Constructivism operates in a mode where management and leadership are situational variables. The management and leadership concepts are guided by a contingency viewpoint. Therefore, knowledge transmission is holistic and complex. It is conceived as a result of empirical processes. In a constructivist classroom, students are actively engaged in education. They share their thoughts and ideas, ask specific questions, revise their thoughts and reject misconceptions [27]. The learning environment is highly cooperative and the teacher is viewed as a collaborator in knowledge acquisition. Active knowledge construction is useful for prolonged learning and social development $[23,25,26]$.

One way to implement new strategies in science teaching is to incorporate scientific elements into project assignments within the curriculum, which we also tried to do in our work. Project-based education should reflect real research work as closely as possible. We chose project teaching also because, at the level of lower secondary education in Slovakia, the State Educational Program [28] introduced the creation of projects and the development of presentation skills as one of eight cross-cutting themes. The primary objective of our work was thus to verify the effectiveness of project-based science teaching via Integrated e-Learning in the 9th grade at two elementary schools in Slovakia. The outcome was compared with traditional (instructionist) teaching. This work is a pilot study focused on the possibility of applying project-based teaching via INTe-L in Slovakia. The goal of our pedagogical research was to determine the applicability of project teaching via an INTe-L strategy for the topic "Energy Sources" in the physics curriculum.

Real and virtual experimentation is an integrated part of the INTe-L strategy. It enables remote access to and control of physical experiments along with the transfer of experimental data. Project teaching using the INTe-L strategy (real on-site and real remote experiments, simulations and electronic educational materials) makes extensive use of the latest information and communication technologies (ICTs). Simulations of real experiments are also possible. Teachers at all school levels can incorporate these approaches into 
their curriculum. The INTe-L may find its use at the time of the COVID-19 pandemic, when schools and universities are moving away from contact to distance forms of education.

\section{Materials and Methods}

During two school years, we conducted pedagogical research on physics lessons in the 9th grade of two Slovak primary schools. The main objective was to determine the suitability of project-based teaching using components of the INTe-L strategy for the topic "Energy Sources".

\subsection{Research Sample}

The research sample was selected based on convenience sampling and consisted of 155 pupils from the 9th grade in primary schools from western Slovakia. One school was from Trnava and one from the Nitra region. The pupils were divided into two groups: an experimental group (EG) of 85 pupils and a control group (CG) of 70 pupils. The pupils of the 9th grade of elementary school who had worse results in physics compared to the parallel class were included in the EG.

\subsection{Instrument and Procedures}

Before carrying out the pedagogical research, we conducted pre-research on a small sample of 18 pupils from the 9th grade of a primary school. In this way, we wanted to achieve high validity for our research tools and ensure that they were able to detect what was intended. The pre-research was carried out one year before the main research. It was focused on verifying the possibility of using the INTe-L strategy in project-based teaching, detection of potential drawbacks and determining whether the research instruments work. We investigated whether:

- the persons under investigation understood the instructions given to them;

- the participants understood the issues in our research tools;

- the pupils understood the tasks in the project assignment;

- the educated persons were able to develop projects based on the project assignment;

- the project work took as much time as we planned (two weeks);

- the collected data could be evaluated.

Based on the pre-research, we designed the learning concept and optimized the number of lessons and the number of tasks. The optimized curriculum is provided in Table 1.

Table 1. Time-thematic plan for teaching the topic "Energy Sources".

\begin{tabular}{|c|c|c|}
\hline Lesson No. & Topic & Specific Aims \\
\hline 1 & $\begin{array}{l}\text { Energy Sources } \\
\text { Electric Energy }\end{array}$ & $\begin{array}{c}\text { To characterize the different energy sources; electric energy- } \\
\text { its importance and production }\end{array}$ \\
\hline 2 & Fossil Fuels & $\begin{array}{l}\text { To characterize different fossil fuels, explain their production, } \\
\text { advantages and drawbacks }\end{array}$ \\
\hline 3 & Renewable Energy Sources & $\begin{array}{l}\text { Green energy sources, solar, water, wind and } \\
\text { geothermal energy, small hydropower plants in Slovakia }\end{array}$ \\
\hline 4 & $\begin{array}{l}\text { An Increasing Energy Consumption and } \\
\text { its Adverse Effects }\end{array}$ & $\begin{array}{l}\text { The optimization of energy consumption in a } \\
\text { typical household, minimization of energy losses, } \\
\text { responsible energy consumption }\end{array}$ \\
\hline
\end{tabular}

It was decided that the topic would be taught over the course of two weeks. Since two lessons of physics per week were provided in each school, the entire teaching activity included four different lessons.

In the second year, we proceeded with the pedagogical experiment. We presented the pupils with a non-standardized didactic entrance test (pre-test) through which we investigated the level of the pupils' pre-entry knowledge. The reason was that pre-entry knowledge, if it was very different in the individual groups, could influence the results of the post-tests later. During the preparation of the 
pre-test, we proceeded from the standard in [28]. This standard defines the level of knowledge at the end of the 8th year of elementary school. The 9th grade pupils should know:

- how to apply relationships to calculate work and power of objects;

- how to explain, through simple examples, the interconversion of different forms of energy and the law of energy conservation;

- how to explain the concept of heat and apply the appropriate relation to heat calculation from the calorimetric equation;

- how to explain the concept of the internal energy of an object and the concept of friction;

- how to characterize the change in the internal energy of an object during heat exchange and during work.

The education in the EG and CG during the main research had the following aspects:

- it was conducted on the same subject (physics);

- the same topic, "Energy Sources", was taught;

- the physics teachers had the same qualifications;

- the teachers had more than ten years' experience in education.

In the EG, we conducted project-based teaching. Prior to the actual execution of the project, the pupils were acquainted with the topic of the project, with its objectives, tasks and with the method of assessment. Subsequently, they were divided into groups of three. After consulting the physics teacher, each group selected one member for each of the following roles:

- helper: a pupil who brings the necessary materials and helps the group to stay within the given topic;

- recorder: a pupil who records the suggestions, procedures and work notes from all group members;

- reader: a pupil who reads out loud the instructions and results to the others;

- quieter: a pupil who looks out for the teacher's signal for active listening and quiets the group down;

- organizer: a pupil who organizes the work on the project and is responsible for the cleanliness and organization of the workplace;

- $\quad$ presenter: a pupil who presents the project results in front of the whole class.

Since the groups had three members, each member was assigned two roles.

The project teaching in the EG used the following teaching methods: project and problem definition, multimedia, dialogic methods (interview, discussion), work with textbooks and books, demonstration methods, practical activities with pupils, research methods, methods of repetition and practice and group work. The pupils chose the form of project presentation and systematically started working on the project outcomes based on the proposed assignment with the inclusion of all INTe-L strategy elements. Posters and PowerPoint slides were most frequently used as project presentations. At the end, there was a presentation of the project results in front of the class, discussion and evaluation, all based on criteria given beforehand.

In the CG, we taught the given topic in a traditional (instructionist) way. The same curriculum, given in Table 1, was taught in the EG and CG. The different teaching approaches applied in the EG and CG are compared in Table 2. The knowledge in the CG was passed on in one direction, i.e., pupils were instructed by teachers without their active engagement in practical demonstration. The curriculum was narrated by the teacher and transferred to pupils via monologue (description and explanation on the blackboard). We also worked with textbooks and used visual demonstration methods; however, the teacher always demonstrated the experiment in front of the students and pupils were only passive recipients of information and results. Discussion was limited to a period towards the end of the lesson, when teachers finished their instruction. The knowledge was repeated at the beginning of the next class with only one selected pupil answering the teacher's questions. 
Table 2. Teaching approaches used in the control group (CG) and experimental group (EG) during pedagogical experiment.

\begin{tabular}{cc}
\hline CG (Instructionism Approach) & EG (Project-Based Teaching via INTe-L) \\
\hline Teachers were active instructors and demonstrators. & $\begin{array}{c}\text { Teacher was an advisor and facilitator who guided students } \\
\text { and provided impulses. }\end{array}$ \\
\hline Students were passive recipients of knowledge. & $\begin{array}{c}\text { Students were actively engaged in experiments } \\
\text { and simulations. }\end{array}$ \\
\hline $\begin{array}{c}\text { Results were given beforehand, together with a } \\
\text { straightforward explanation. }\end{array}$ & $\begin{array}{c}\text { Teaching was based on real situations that can be encountered } \\
\text { in everyday life. }\end{array}$ \\
\hline $\begin{array}{c}\text { Vertical relationship between teacher and student was maintained: } \\
\text { teacher asked questions and pupils replied. }\end{array}$ & $\begin{array}{c}\text { Horizontal relationship and dialogue between teacher and } \\
\text { pupils were developed. }\end{array}$ \\
\hline Dialogue and discussion between pupils were discouraged. & Dialogue and discussion between students were encouraged. \\
\hline
\end{tabular}

After conducting the pedagogical experiment, we presented the EG and CG with a non-standardized didactic output test (post-test). When creating a post-test on the topic "Energy Sources", we proceeded from the standard in [28]. According to this standard, a pupil from the 9th grade of elementary school should know:

- what solar energy is, its importance and transformations;

- how to explain the formation and types of fossil fuels and characterize their advantages and drawbacks;

- how to describe the use of solar, hydroelectric, wind and geothermal energy sources and explain the importance of small hydropower plants.

We tried to ensure the high reliability of the research tools by placing emphasis on the following three basic factors:

- the scope of research tools-a sufficient number of items;

- homogeneity (coherence) of research instruments—-the instrument items were similar in content;

- $\quad$ adequate research tools.

When developing didactic tests (DTs) (pre-test and post-test), we followed a general algorithm [29]. We consulted with the teachers of the elementary schools where we carried out the pedagogical experiment for all tasks, as well as with the methodologist for teaching physics at the Methodological-Pedagogical Center in Bratislava.

\section{3. "Energy Sources"-Project Definition for the EG}

Task 1: Conduct the following experiments.

Experiment 1: Solar collector.

Aim: Verify the use of solar energy for water heating in solar collectors.

Tools: Cardboard shoe box, black paint, transparent foil or glass board, flexible hose, funnel, screws and assembly tools, scotch tape, scissors, two cork arrests, bucket for water collection, thermometer, clock, water.

Instructions:

(a) Measure the water temperature with a thermometer.

(b) Close one end of the tube with a cork arrest.

(c) Fill in the tube with water. Use a funnel to pour the water in. Close the other end of the tube with a cork arrest.

(d) Paint the inner walls of the cardboard box with black paint.

(e) Drill two small openings in the opposite walls of the cardboard box and mount the tube in these openings.

(f) Place a transparent lid on the box. 
(g) Place the solar collector (Figure 2) outdoors on a sunny day.

(h) Pour the water out of the tube after $30 \mathrm{~min}$ and check its temperature.

(i) Make more experiments with the solar collector and check how the water temperature changes over time or with the angle of solar radiation.

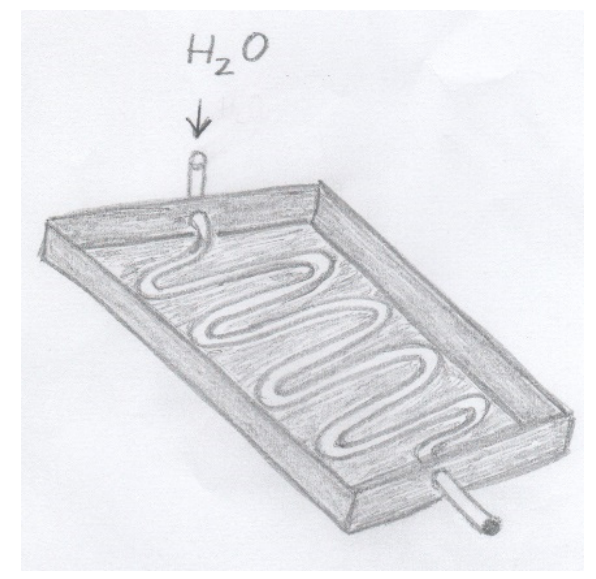

Figure 2. Solar collector.

Experiment 2: Waterwheel

Aim: Investigate the energy of the water flow.

Tools: A wooden board, a larger cork arrest (diam. $3.5 \mathrm{~cm}$ ), plastic foils, wood sticks, thread, O-ring, saw, glue, scissors, weight.

Instructions:

Prepare a waterwheel from a cork stopper using the following procedure:

(a) Drill a central hole in the cork stopper and push a wooden stick inside.

(b) Make six indents on the circumference of the stopper.

(c) Cut six thin plastic sheets from an ice-cream box to make blades. Glue them into the dents.

(d) Drill a hole on one end of a wooden prism and push a plastic straw inside.

(e) Place the axis of the waterwheel into the straw.

(f) Place the waterwheel into a sink (Figure 3).

(g) Tie up a sinker of a known mass on one end of the waterwheel.

(h) Turn on the water and let it run on the blades of the turbine. Running water will start turning the wheel which will make the sinker move up. You can calculate the power of the water turbine using the following equation:

$$
P=\frac{m g h}{t}
$$

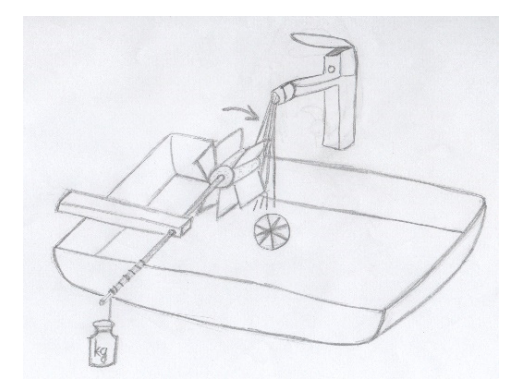

Figure 3. Waterwheel. 
In this equation, $m$ is the sinker mass, $h$ is the length of the string and $t$ is the running time.

Task 2: Go to www.ises.info and open the "e-Laboratory Project" link [30]. In the section "Remote Laboratory", open the real remote experiment entitled "Solar energy conversion". Click on "Run experiment". Think of the energy transformations taking place during the experiment.

Task 3: Open the following links:

- $\quad$ https://www.seas.sk/hydro-electric-power-plants [31].

- https://www.seas.sk/photovoltaic-power-plants [32].

- $\quad$ https://www.seas.sk/nuclear-power-plants [33].

- https://www.seas.sk/thermal-power-plants [34].

Explore how the thermal, nuclear, water and solar power stations work. Think of the energy transformations taking place in these power stations.

Task 4: Go to https://www.seas.sk/biomass [35] and find out what biomass is and what it is used for.

Task 5: Based on the previous studies, answer the following questions:

(a) Name a few examples of fossil fuels. What are the conditions for their formation?

(b) Explain the advantages and disadvantages of fossil fuels.

(c) Name a few examples of renewable energy sources.

(d) What is the source of solar energy? How is solar energy produced?

(e) What is the name of the solar reaction?

(f) Describe the effects of solar radiation on human health.

(g) Describe the solar energy transformations observable in nature. Which of them are utilized by humankind?

(h) Describe the uses of solar energy.

(i) Why can't wind turbines fully replace thermal power stations?

(j) How is geothermal energy produced?

(k) In which countries is geothermal energy most frequently used?

(l) Where in Slovakia is geothermal energy produced?

Task 6: Based on the information collected, make a project presentation titled "Energy Sources".

Project objectives and cognitive processes within the study curriculum: Data collection. Data evaluation. Discussion, cooperation and problem-solving during project execution. Work with the World Wide Web and scientific literature. Cooperating and becoming responsible for a specific research task. Presentation of results. Description of the energy significance for the humankind. Description of the worldwide energy crisis. Fossil fuels and renewable energy sources. Explanation of how people, animals and plants collect and use energy. Path of energy transformation in nature.

Time duration: 2 weeks.

Project evaluation: A score of 1-20 points for which each pupil obtains a maximum of 10 points for the quality of presentation and 10 points for the understanding.

\subsection{Research Hypotheses}

We assumed that a relationship exists between the pupils' levels of knowledge and the teaching methods, organization forms and teaching resources used in the pupils' learning. As such, the following hypothesis was formulated:

The project-based teaching of the topic "Energy Sources" in the 9th grade in the two studied primary schools based on the INTe-L teaching strategy is more effective than the traditional way of teaching.

In order to verify this hypothesis unambiguously and qualitatively, we divided it into sub-hypotheses. The following three sub-hypotheses were postulated: 
Hypothesis 1 (H1). Prior to the beginning of the experiment, there will not be notable differences between the pre-test results of the CG and EG.

Hypothesis 2 (H2). The post-test results of the EG in the cognitive area in which the chosen topic will be taught through project-based teaching using INTe-L will be significantly superior to the post-test results of the CG in the same cognitive area.

Hypothesis 3 (H3). At the end of the project-based teaching, the pupils of the EG will be more interested in the relationships between physics and our everyday life compared to the pupils of the CG.

\section{Results}

The pre-test consisted of 15 tasks which were not only oriented towards the reproduction of the knowledge gained, but also required the pupils to apply knowledge from their practical life, combine them and search for links. The theme of the pre-test was "Energy, mechanical work, power". One task involved a multiple choice from three options offered, two questions were openly structured with a conventionally constructed sentence structure and the remaining tasks were open-ended statements and fill-in-the-blanks. The maximum pre-test score was 35 . The scores achieved and their distribution are presented in Figure 4. Since the number of pre-test questions was not greater than 20, we selected a weighted scoring method to evaluate the results. The distribution of the CG pre-test score count has a higher kurtosis compared to the standardized normal distribution and has a positive skew. The distribution of the pre-test score count of the EG has a slightly higher kurtosis than the standardized normal distribution and has a positive skew (Figure 4).

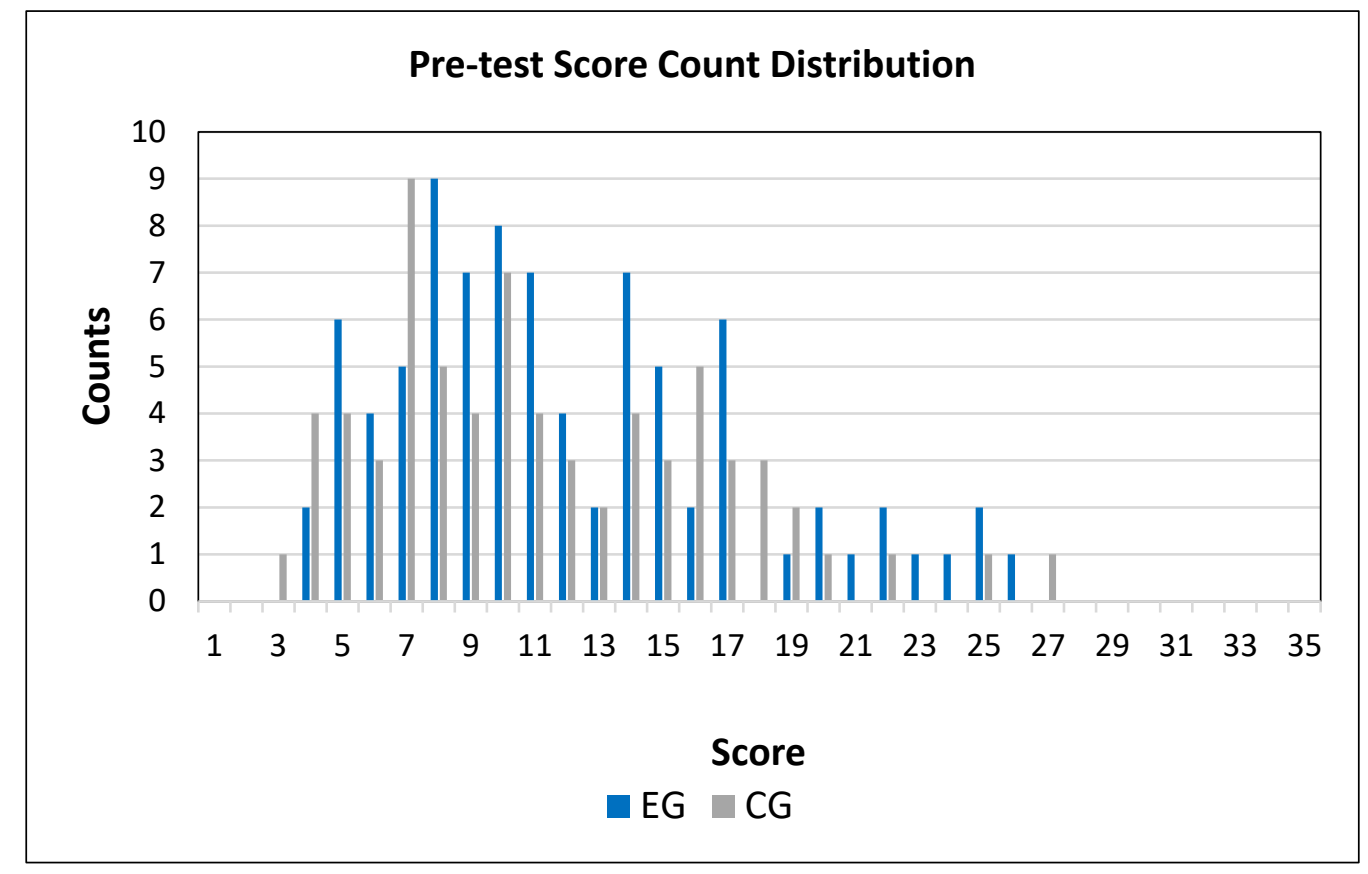

Figure 4. Graphic representation of the pre-test score count distribution for the CG and EG.

The post-test consisted of 14 different questions which were not only oriented towards the mechanical reproduction of the knowledge gained, but also required the pupils to apply knowledge from their practical life, combine them and search for links. The post-test was built around the central theme "Energy Sources". The questions were identical in both the experimental and control groups. Two tasks had multiple choice answers, one question was a sorting task and eleven questions were 
open-ended constructions. The maximum score in the post-test was 19. As the number of questions was smaller than 20, we selected a weighted scoring method to evaluate the results.

The achieved results are presented in Figure 5. The distribution of the post-test score count of the CG has a smaller kurtosis than the standardized normal distribution and has a positive skewness. The distribution of the post-test score count of the EG has a smaller kurtosis than the standardized normal distribution and is also positively skewed. Nevertheless, the distribution in the EG is more symmetrical compared to the CG and a higher average score was obtained.

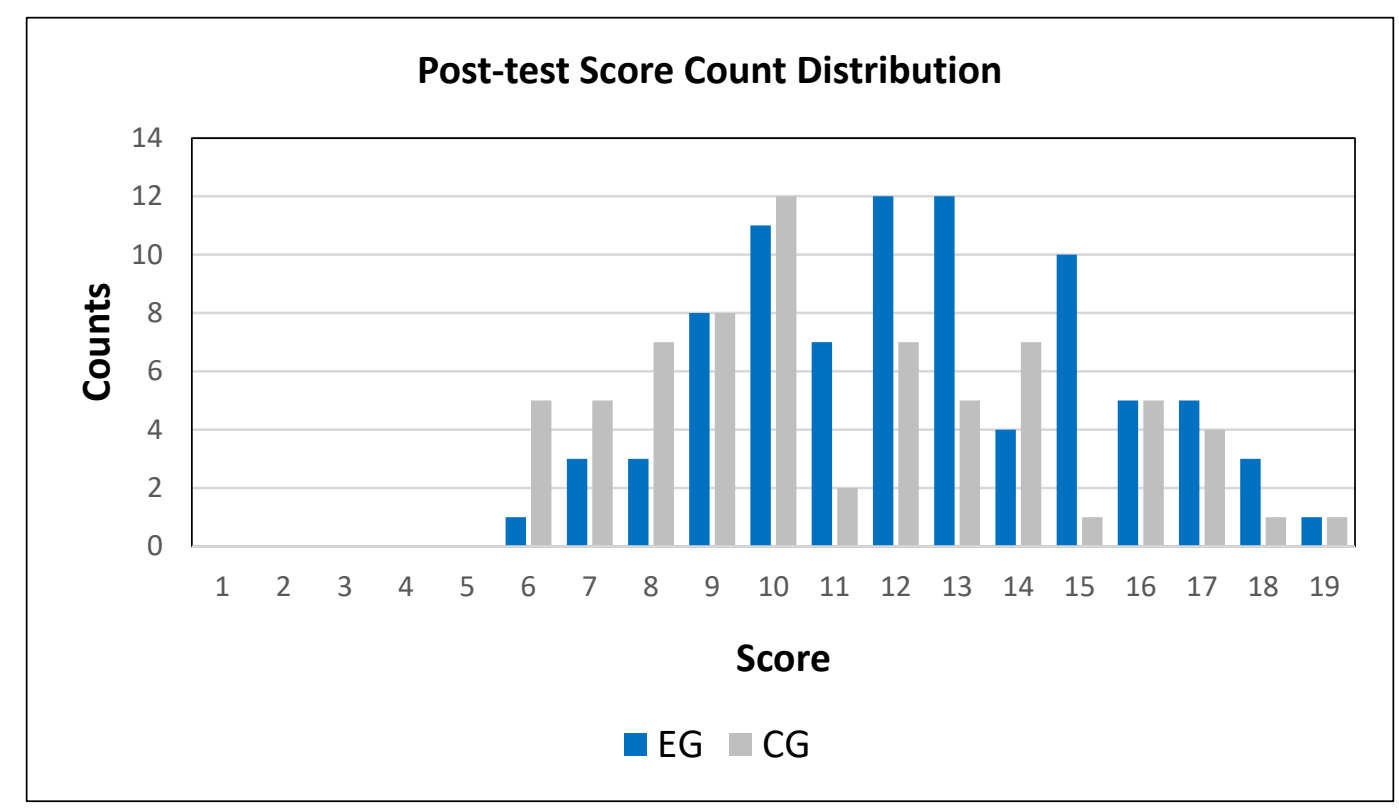

Figure 5. Graphic representation of the post-test score count distribution for the CG and EG.

The statistics of the pre-test results in both EG and CG are presented in Table 3. The maximum and minimum scores achieved, the sample count and other statistical parameters are presented. The confidence level of the EG is 1.17, which means that the distribution center of the pre-test scores lies within the interval $11.96 \pm 1.17$ with $95 \%$ certainty. The confidence level is 1.27 for the CG, which means that the distribution center of the pre-test scores lies within the interval $11.29 \pm 1.27$ with $95 \%$ certainty. The post-tests results are also presented in Table 3. The fourth column shows the maximum and minimum score values achieved in the EG, the sample count and other statistical parameters. The confidence level of the EG is 0.64 , which means that the center of the distribution of the post-test scores is within the interval $12.40 \pm 0.64$ with $95 \%$ certainty. The confidence level of the CG is 0.81 , which means that the center of the distribution lies within the interval $11.17 \pm 0.81$ with $95 \%$ certainty.

The average score of the EG in the post-test was found to be higher compared to the CG (Table 3). To verify whether this difference is of statistical significance, we used two parametric tests: the $F$-test for testing the difference between two variances and Student's $t$-test for testing the difference between two mean values [36,37]. We tested for differences between samples to determine whether there is a statistically significant difference between the populations from which the samples arise or not. We tested against a so-called null hypothesis, i.e., we tested a statement concerning whether zero statistical difference between the two data sets exists. The results of parametric tests are presented below. The results show that there is a statistically significant difference in the post-test scores of the EG and CG. 
Table 3. Statistical parameters of pre-test and post-test scores in the EG and CG.

\begin{tabular}{ccccc}
\hline Statistical Parameter & \multicolumn{2}{c}{ Pre-Test } & \multicolumn{2}{c}{ Post-Test } \\
& EG & CG & EG & CG \\
\hline Mean score & 11.96 & 11.29 & 12.40 & 11.17 \\
Error of the mean & 0.59 & 0.64 & 0.32 & 0.41 \\
Median & 11 & 10 & 12 & 10 \\
Modus & 8 & 7 & 12 & 10 \\
Standard deviation & 5.40 & 5.31 & 2.98 & 3.40 \\
Sample variance & 29.18 & 28.15 & 8.91 & 11.56 \\
Kurtosis & 0.02 & 0.12 & -0.66 & -0.77 \\
Skewness & 0.79 & 0.69 & 0.12 & 0.39 \\
Minimum score achieved & 4 & 3 & 6 & 6 \\
Maximum score achieved & 26 & 27 & 19 & 19 \\
Sum & 1017 & 790 & 1054 & 782 \\
Count & 85 & 70 & 85 & 70 \\
Confidence level (95.0\%) & 1.17 & 1.27 & 0.64 & 0.81 \\
\hline
\end{tabular}

\subsection{Fisher-Snedecor F-Test of Pre-Test and Post-Test Scores}

To see whether the variance in both pre-test data sets was comparable, we used a statistical Fisher-Snedecor F-test. The results are presented in Table 4 . The variance of the results in the EG was 29.18. In the CG, the variance was 28.15. The chosen level of significance $\alpha$ was 0.05 . The test criterion $F=1.04$ (Table 4 ). We can also see that the critical value $F_{0.05}(84 ; 69)=1.47$ and the calculated value $F=1.04$. The critical $F$ value was higher than the calculated value and $P$ was greater than 0.05 . Therefore, we accepted the null hypothesis. As such, we may conclude that differences in the variances in the EG and CG in the pre-test were not statistically significant. As such, the usage of Student's t-test with equal variances can be adopted in the present case.

Table 4. Parameters of binomial F-test for variances in the EG and CG.

\begin{tabular}{ccccc}
\hline \multirow{2}{*}{ Statistical Parameter } & \multicolumn{2}{c}{ Pre-Test } & \multicolumn{2}{c}{ Post-Test } \\
& EG & CG & EG & CG \\
\hline Mean & 11.96 & 11.29 & 12.40 & 11.17 \\
Variance & 29.18 & 28.15 & 8.91 & 11.56 \\
Observation & 85 & 70 & 85 & 70 \\
Difference & 84 & 69 & 84 & 69 \\
$F$ & 1.04 & & 1.29 & \\
$P(F \leq \mathrm{f})(1)$ & 0.44 & & 0.13 & \\
$F$ crit $(1)$ & 1.47 & & 1.46 & \\
\hline
\end{tabular}

To examine whether the variance in both post-test datasets was of the same size, we used the same Fisher-Snedecor $F$-test. The chosen level of significance $\alpha$ was 0.05 . The variance of the EG results was 8.91 (Table 4). The variance of the results in the CG was 11.56. The test criterion $F$ was 1.29 (Table 4). The critical value $F_{0.05}(69 ; 84)$ was 1.46 and the calculated value $F$ was 1.29 . We found that the critical $F$ value was higher than the calculated value and $P$ was greater than 0.05 . As such, we accepted the null hypothesis, i.e., the differences in the variances in both groups in the post-test were not statistically significant. Therefore, Student's $t$-test with equal variances can be applied in the present case.

\subsection{Student's T-Test for Pre-Test and Post-Test Scores}

Student's $t$-test was applied to identify whether the means of two data sets significantly differ from each other. The null hypothesis in the Student's $t$-test for the pre-test was tested using the criteria $t$. The selected significance level $(\alpha)$ was 0.05 . We calculated the value for $t$ and compared it with the critical value of the test criteria for the selected $\alpha$ level and the matching number of the degrees of 
freedom (f), which was in the present case 153. The results are given in Table 5. The critical value of the Student's $t$-test for our number of degrees of freedom and the chosen $\alpha$ level was $t_{0.05}(153)=1.98$.

Table 5. Binomial $t$-test results with homogeneity of variance.

\begin{tabular}{ccccc}
\hline \multirow{2}{*}{ Statistical Parameter } & \multicolumn{2}{c}{ Pre-Test } & \multicolumn{2}{c}{ Post-Test } \\
& EG & CG & EG & CG \\
\hline Mean & 11.96 & 11.29 & 12.40 & 11.17 \\
Variance & 29.18 & 28.15 & 8.91 & 11.56 \\
Observation & 85 & 70 & 85 & 70 \\
Common variance & 28.71 & & 10.11 & \\
Hyp. difference of means & 0 & & 0 & \\
Difference & 153 & & 153 & \\
$t$ stat & 0.79 & & 2.39 & \\
$P(\mathrm{~T} \leq \mathrm{t})(1)$ & 0.22 & & 0.0089 & \\
$t$ crit $(1)$ & 1.66 & & 0.018 & \\
$P(\mathrm{~T} \leq \mathrm{t})(2)$ & 0.43 & & 1.98 & \\
$t$ crit $(2)$ & 1.98 &
\end{tabular}

The calculated $t$ value was 0.79 (Table 5). Since the calculated $t$ value was smaller than the critical value and $P$ was greater than 0.05 , we had to admit a null hypothesis. We can conclude that the differences between the pre-test results of the EG and CG were not statistically significant.

We also examined the null hypothesis in the Student's test for the post-test using the $t$ criteria. The same level of significance was chosen $(\alpha=0.05)$. We calculated the value for $t$ and compared it with the critical value of the test criteria for the selected $\alpha$ and the same number of degrees of freedom $(f=153)$. The critical value was $t_{0.05}(153)=1.98$ (Table 5). The calculated $t$ value was 2.39 . The calculated value was higher than the critical one and $P$ was smaller than 0.05 . These results show that in the post-test scores of the EG and CG there was a statistically significant difference and the null hypothesis must be rejected.

\subsection{Verification of H3 Hypothesis}

Each pupil was interviewed after the execution of the project-based teaching. Since the size of the group was rather large (155 pupils), we present herein only the statistics of the responses obtained. The major results are provided in Table 6. From the results it can be observed that pupils of the EG became more interested in physics and its applications in real life compared to the CG.

Table 6. Questions and responses to the interviews conducted with the EG and CG after teaching.

\begin{tabular}{c} 
Did you like physics before? \\
EG: $47 \%$ said no, $35 \%$ said yes and $18 \%$ did not know. \\
CG: $42 \%$ said no, $26 \%$ said yes and $32 \%$ did not know. \\
EG: Have you changed your attitude towards physics now after the project-based teaching has been concluded? \\
$35 \%$ were positive, $24 \%$ were negative, $41 \%$ were neutral \\
CG: Have you changed your attitude towards physics now after studying the "Energy Sources" topic? \\
$19 \%$ were positive, $32 \%$ were negative, $49 \%$ were neutral \\
\hline EG: Do you think that the "Energy Sources" project work helped you to understand the applications of physics in \\
real world problems? \\
$55 \%$ of respondents were affirmative, $29 \%$ were neutral and $16 \%$ were negative. \\
CG: Do you think that the "Energy Sources" topic helped you to understand the relationships between physics \\
and real-world problems? \\
$15 \%$ of respondents were affirmative, $43 \%$ were neutral and $42 \%$ were negative.
\end{tabular}

\section{Discussion}

The statistical analysis of the results achieved by the pupils participating in our pedagogical experiment demonstrate the applicability of introducing and further implementing project-based 
teaching based on the INTe-L education strategy into the pedagogical process in the 9th grade in two primary schools in Slovakia for the topic "Energy Sources". The pedagogical research proved the hypotheses H1, $\mathrm{H} 2$ and $\mathrm{H} 3$ at the level of significance $\alpha=0.05$ (Table 7).

Table 7. The validity of the hypotheses and the studied variable.

\begin{tabular}{cccc}
\hline Hypothesis & Data Acquisition Method & $\begin{array}{c}\text { Validity of } \\
\text { Hypothesis }\end{array}$ & Studied Variable \\
\hline$H 1$ & Entrance didactic test (pre-test) & Valid & $\begin{array}{c}\text { Level of initial knowledge in the } \\
\text { cognitive area }\end{array}$ \\
H2 & Output didactic test (post-test) & Valid & $\begin{array}{c}\text { Level of output knowledge in the } \\
\text { cognitive area } \\
\text { M3 }\end{array}$ \\
Interview & Valid & Motivation \\
\hline
\end{tabular}

Based on these findings we can claim that the project-based teaching with INTe-L elements for the topic "Energy Sources" in the 9th grade of the two primary schools was more effective than the traditional (instructional) way of teaching.

The students' attitudes towards science, technology, engineering and mathematics (STEM) were negative [38]. The purpose of our work was thus to change the pupils' negative attitudes towards physics and science in general and to inspire their interest and enhance their learning autonomy. The negative attitudes towards physics, as also revealed by our interview, were enabled by the lack of practical examples during traditional learning (25\%) and boredom during classes (23\%) (Figure 6). As such, it is essential to enhance the traditional approach to physics teaching by introducing new elements, methods and styles and, at the same time, take into account the problems of the real world. We can thus speak of a transition from teaching based on a behavioral theory to teaching based on a constructivist theory and of computer usage in this teaching [39-41]. A very important feature of the constructivist education reform is the change of the teacher's position from that of a provider of knowledge to a facilitator, who accompanies pupils and students on their quest for knowledge. The construction of knowledge is an active process and pupils must be given the opportunity to work with the curriculum. Great emphasis should be given to cross-curricular relationships and preparation for teamwork [42-44].

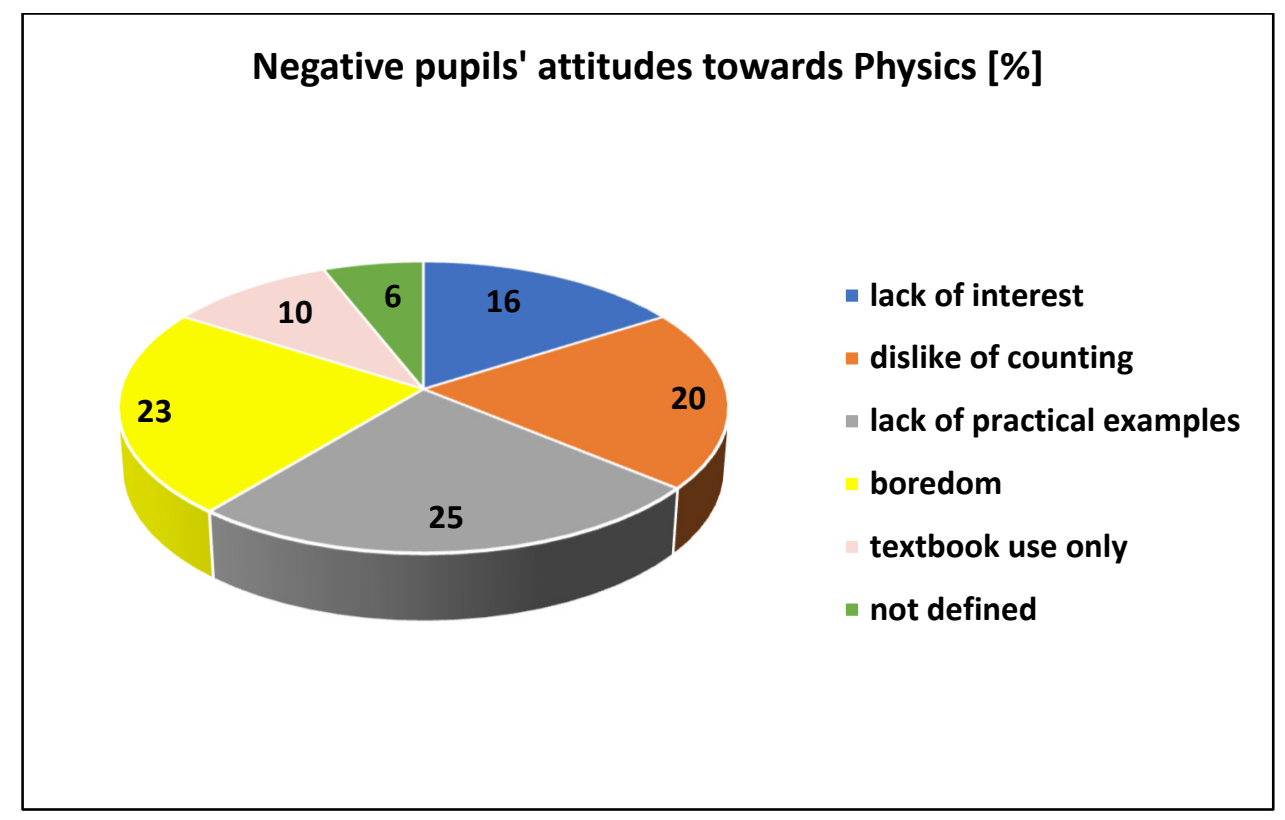

Figure 6. The pupils' negative attitudes towards physics and their distribution, as revealed by our interview. 
The positive change in pupils' attitudes towards physics after the execution of our project-based teaching is remarkable (Table 6). Pupils appreciated that "the topic was close to their real life" (21\%) (Figure 7). Furthermore, they enjoyed working in the team (10\%) and liked working with the computer $(14 \%)$. The respondents also said that the project gave them "a great deal of new information". They also appreciated the opportunity to defend their work. A positive improvement in students' attitudes towards physics was also observed by other authors who implemented project-based learning [45-47]. When we asked pupils to name any drawbacks, a large part of the group $(91 \%)$ could not find any. Only a small portion of pupils said that they did not like the high number of tasks in the project $(9 \%)$.

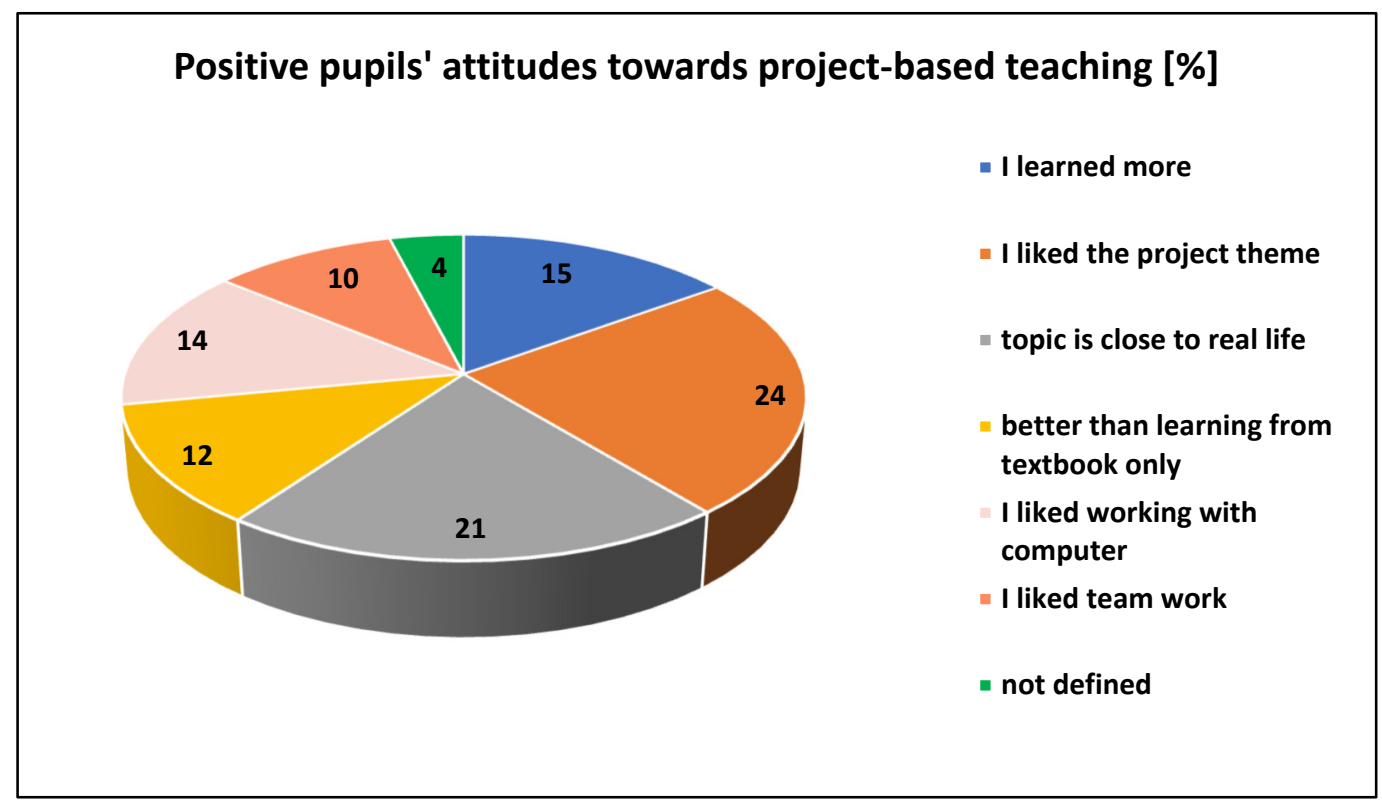

Figure 7. Pupils' positive attitudes towards project-based teaching and their distribution.

As opposed to conventional ways of teaching, project-based teaching allows pupils to experience relative freedom. The emphasis is placed on their independent fieldwork and experimenting. As such, it is not merely a passive reception of ready-made information. For example, as Skalková [48] states, project-based teaching focuses on the pupil's own experience. The experience is based on the human's active relationship to their natural and social environment. The aim is not only a spontaneous gaining of experience, but also reflecting on, processing and evaluating it. Project-based teaching is built on the assumption that knowledge cannot be separated from an activity, the work of one's head from the work of one's hands [49].

The need for the diversification of teaching methods is now widely addressed by education researchers $[23,25,26]$. Nevertheless, the implementation of curriculum reforms and integration of education technologies may be challenging for schools and universities. The core value of constructivism is active student involvement, driven by student interest, motivation and personal satisfaction. However, direct instruction, although mechanistic and dehumanizing, is highly effective in facilitating student skill acquisition [22,23]. Active learning is at the upper corner of a triangular framework formed by student-led constructivism, teacher-led instructionism and learning materials [50]. The three components of the teaching strategy interact and constitute an intended learning outcome. The teaching of a new topic should be initiated from instructionism and a so-called instructor's perspective could be utilized to start the discussion and transmit the central knowledge to the recipients. In the second step, the pupils start to construct new knowledge in their minds based on their previous real-life experiences and interests. A personal experiential profile is created as a result of the learner's previous experience [50]. It is now agreed that a combination of different teaching methods is the most beneficial for pupils. Intense teacher-driven lessons should be evenly distributed throughout the school day, thereby minimizing 
mechanical learning and maximizing the pupil's potential. A combined instructionist-constructivist approach is probably the most useful as it can promote a pupil's systematic advancement within the context of an individual approach and personal interests. It should, however, be combined with suitable learning materials. In the triangular network, learning materials play a critical role as they provide core knowledge [50]. Learning materials can be provided in the form of e-books, e-demonstrations or e-simulations on the Internet.

A basic element of science is the experiment. Modern types of experiments include computer-aided laboratory experiments, real remote experiments on the Internet, virtual experiments (interactive simulations) mediated via the World Wide Web and electronic education materials [6]. INTe-L is based on scientific work methods whose main features are work organization and planning, observation of real world phenomena, experimenting, formulating assumptions, testing hypotheses, searching for and recording information, presenting acquired data in tables and graphs, subsequent data analysis and processing and formulating conclusions [5]. It is important to proceed from observation and experimentation to the creation of conceptual structures and models and up to gaining knowledge about the natural science laws. The scientific procedures of the INTe-L education strategy enabled us to formulate scientific questions and search for the links between theoretical knowledge and the real-world experience around us. All three components of INTe-L bring new opportunities into project-based teaching which can be suitably used in science and technology subjects, where the experiment is an essential component of education. As the present study has shown, the effective use of ICT can make physics a more interesting subject for pupils.

Tkáč [51] conducted research on a sample of technical university students. He found that the use of interactive remote experiments can positively motivate students. The implementation of the experiment into the educational process through the INTe-L strategy allows students to understand the curriculum more deeply, while significantly improving their attitude towards study. This was ultimately reflected in the knowledge gained during electronics teaching. Başer and Durmuş [52] were also supportive of the scientific experiment in education. Thornton [53], Wieman-Perkins [4] and Mattute-Vadilo [54] found that students who performed real-time measurements during their studies had a significantly higher success rate in understanding the underlying concepts compared to students who were taught traditionally. The attitudes of students towards science were also significantly improved [55]. This positive motivation is reflected not only in the acquired knowledge and better understanding of the physical phenomena, but also in the students' persistence and desire to successfully complete their study.

The latest school reform in Slovakia, launched on 1 September 2008, allows teachers and pupils to use individual activating approaches. A basic characteristic of project-based teaching is the use of cross-curricular relationships. A compulsory part of the educational curriculum implemented by the State Education Program in Slovakia contains cross-sectional topics which generally overlap several educational areas. Among these is also a cross-sectional topic "Project Creation and Presenting Skills". In light of these developments, it is possible to use the assignment prepared by us directly in physics and other science and technology subjects.

\section{Conclusions and Future Suggestions}

This study presented the results of two-year-long pedagogical research. The research was conducted on the teaching of the subject of physics in the 9th grade at two primary schools in the Slovak republic and the topic "Energy Sources" was taught via INTe-L. The components of INTe-L are the following: (a) real on-site and real remote experiments, (b) virtual experiments and interactive e-simulations and (c) electronic educational materials. We carried out a pedagogical experiment on a sample of 155 respondents. The results attained in the experimental group were statistically processed, evaluated and subsequently compared with those in control group (CG). A two-phase test with dispersion equality proved that differences in the pre-test scores in the EG and CG were not statistically significant. The differences in the final didactic test (post-test) results achieved in the EG 
and CG, on the other hand, were statistically significant and better scores in the EG were obtained. A positive change in pupils' attitudes towards physics in the EG after the execution of our project-based teaching was noted. The evaluation of the results attained by pupils proved that the introduction of project-based teaching via INTe-L is an effective strategy to improve physics teaching. As such, the implementation of this interactive strategy in the instructional education process at primary schools is recommended.

Technology and natural science subjects contain many abstract concepts that are often misunderstood by primary school pupils. Therefore, misconceptions may arise and incorrect information could be planted in the pupils' memory. Project-based teaching with an INTe-L strategy introduces new possibilities into the educational process. The aim of INTe-L is to combine the instructionist teaching of natural sciences and technology with experimenting, thereby educating pupils in a more interesting, more interactive and unusual way compared to the traditional way of teaching.

One of the core characteristics of project-based teaching is an effective use of cross-curricular relationships. The search for cross-curricular links between different subjects is encouraged as they help to consolidate the acquired knowledge. From this perspective, it is possible to use the assignment prepared by us directly in physics and other related science and technology subjects (e.g., chemistry, materials science). Based on the methodology of project creation with INTe-L elements, teachers can design and create their own project assignments for various topics in STEM subjects.

Author Contributions: conceptualization, Ž.G. and M.P.; methodology, Ž.G.; formal analysis, Ž.G. and M.P.; investigation, Ž.G. and M.P.; resources, Ž.G. and M.P.; data curation, Ž.G., P.P. and M.P.; writing—original draft preparation, Ž.G.; writing_-review and editing, Ž.G. and M.P.; supervision, Ž.G. and M.P. All authors have read and agreed to the published version of the manuscript.

Funding: This research was funded by Vedecká Grantová Agentúra MŠVVaŠ SR a SAV: 1/0490/18 and Vedecká Grantová Agentúra MŠVVaŠ SR a SAV: 1/0235/18.

Conflicts of Interest: The authors declare no conflict of interest.

Ethical Statement: No personal information was collected from human participants, and data presented in this paper are not traceable to individual participants. All procedures involving humans were in accordance with the ethical standards of the institutional and/or national research committee.

Consent Statement: Informed consent was obtained from all individual participants included in the study.

\section{References}

1. Feynman, R.P.; Leighton, R.B.; Sands, M. The Feynman Lectures on Physics 1; CRC Press: Baton Rouge, LA, USA, 2018; ISBN 978-0-7382-0296-9.

2. $\quad$ PISA OECD. Available online: https://www.oecd.org/pisa/data/ (accessed on 4 November 2020).

3. Chen, C.S.; Lin, J.W. A practical action research study of the impact of maker-centered STEM-PjBL on a rural middle school in Taiwan. Int. J. Sci. Math. Educ. 2019, 17, 85-108. [CrossRef]

4. Wieman, C.; Perkins, K. Transforming Physics Education. Phys. Today 2005, 58, 36-41. [CrossRef]

5. Ožvodlová, M.; Gerhátová, Ž. Energy and its Transformation-Primary School Project Based Education Using Integrated E-learning. Proceedia Soc. Behav. Sci. 2013, 89, 5-9. [CrossRef]

6. Schauer, F.; Ožvoldová, M.; Lustig, F. Integrated e-Learning-New Strategy of Cognition of Real World in Teaching Physics. In Innovations 2009_World Innovations in Engineering Education and Research Potomac; Aung, W., Kim, K.S., Mecsi, J., Moscinski, J., Eds.; iNEER: Potomac, MD, USA, 2009; pp. 119-135.

7. Eckert, B.; Gröber, S.; Jodl, H.J. Distance Education in Physics via the Internet. Am. J. Distance Educ. 2009, 23, 125-138. [CrossRef]

8. Perez-Navarro, A.; Garcia, V.; Conesa, J. Students perception of videos in introductory physics courses of engineering in face-to-face and online environments. Multimed. Tools Appl. 2020. [CrossRef]

9. Ramirez Diaz, M.H.; Rodriguez Castillo, M.; Viramontes, I.M. Use of Facebook to Learn Photovoltaic Theory. Sci. J. Educ. 2018, 6, 22-38. [CrossRef]

10. Chandra, S.; Sharma, B. Near, Far, Wherever You Are: Chemistry via Distance in the South Seas. Am. J. Distance Educ. 2018, 32, 80-95. [CrossRef] 
11. Pedaste, M.; Mäeots, M.; Siiman, L.A.; de Jong, T.; van Riesen, S.A.N.; Kamp, E.T.; Manolli, C.C.; Zacharia, Z.C.; Tsourlidaki, E. Phases of Inquiry-Based Learning: Definitions and the Inquiry Cycle. Educ. Sci. Rev. 2015, 14, 47-61. [CrossRef]

12. Dobber, M.; Zwart, R.; Tanis, M.; van Oers, B. Literature review: The role of teacher in inquiry-based education. Educ. Res. Rev. 2017, 22, 194-214. [CrossRef]

13. Kokotsaki, D.; Menzies, V.; Wiggins, A. Project-based learning: A review of the literature. Improv. Sch. 2016, 19, 267-277. [CrossRef]

14. Al-Balushi, S.M.; Al-Aamri, S.S. The effect of environmental science projects on students' environmental knowledge and science attitudes. Int. Res. Geogr. Environ. Educ. 2014, 23, 213-227. [CrossRef]

15. Wurdinger, S.; Haar, J.; Hugg, R.; Bezon, J. A qualitative study using project-based learning in a mainstream middle school. Improv. Sch. 2007, 10, 150-161. [CrossRef]

16. Thomas, J.W. A Review of Research on Project-Based Learning. 2000. Available online: https://www.nido.cl/ uploaded/pblresearch2.pdf (accessed on 28 November 2020).

17. Helle, L.; Tynjälä, P.; Olkinuora, E. Project-based learning in post-secondary education-Theory, practice and rubber sling shots. High. Educ. 2006, 51, 287-314. [CrossRef]

18. Holubova, R. Effective teaching methods-Project-based learning in physics. US China Educ. Rev. 2008, 5, 27-35.

19. Barak, M. From "doing" to "doing with learning": Reflection on an effort to promote self-regulated learning in technological projects in high school. Eur. J. Eng. Educ. 2012, 37, 105-116. [CrossRef]

20. Bell, S. Project-based learning for the 21st century: Skills for the future. Clear. House J. Educ. Strateg. Issues Ideas 2010, 83, 39-43. [CrossRef]

21. Zhenlin, W. Theory of mind and children's understanding of teaching and learning during early childhood. Cogent Educ. 2015, 2, 1011973. [CrossRef]

22. Pitsoe, V.J. From an Instructionist to a Constructivist Classroom Management: A Dialogue. Int. J. Educ. Sci. 2014, 7, 391-399. [CrossRef]

23. Johnson, G.M. Instructionism and constructivism: Reconciling two very good ideas. Int. J. Spec. Educ. 2009, 24, 90-98.

24. Kruger, A.G. Classroom management. In School Management: The Task and Role of the Teacher; Kagiso Publishers: Pretoria, South Africa, 1995; pp. 39-54.

25. Khalaf, B.K.; Zin, Z.B.M. Traditional and Inquiry-Based Learning Pedagogy: A Systematic Critical Review. Int. J. Instr. 2018, 11, 545-564. [CrossRef]

26. De Jong, T. Moving towards engaged learning in STEM domains, there is no simple answer but clearly a road ahead. J. Comput. Assist. Learn. 2019, 35, 153-167. [CrossRef]

27. Jonassen, D.H.; Myers, J.M.; McKillop, A.M. From constructivism to constructionism: Learning with hypermedia/multimedia rather that from it. In Constructivist Learning Environments: Case Studies in Instructional Design; Educational Technology Publications: Englewood Cliffs, NJ, USA, 1996; pp. 93-106.

28. The National Educational Program. 2008. (In Slovak). Available online: https://www.statpedu.sk/sk/svp/ statny-vzdelavaci-program/ (accessed on 4 November 2020).

29. Hrmo, R.; Kundrátová, M.; Tináková, K.; Vašková, L'. Didaktika Technických Predmetov; Slovak University of Technology: Bratislava, Slovakia, 2005; ISBN 80-227-2191-3. (In Slovak)

30. Lustig, F. e-Laboratory Project. Available online: http://www.ises.info/index.php/en/ises (accessed on 4 November 2020).

31. Hydroelectric Power Plants. Available online: https://www.seas.sk/hydro-electric-power-plants (accessed on 4 November 2020).

32. Photovoltaic Power Plants. Available online: https://www.seas.sk/photovoltaic-power-plants (accessed on 4 November 2020).

33. Nuclear Power Plants. Available online: https://www.seas.sk/nuclear-power-plants (accessed on 4 November 2020).

34. Thermal Power Plants. Available online: https://www.seas.sk/thermal-power-plants (accessed on 4 November 2020).

35. Biomass. Available online: https://www.seas.sk/biomass (accessed on 4 November 2020).

36. Markowski, C.A.; Markowski, E.P. Conditions for the Effectiveness of a Preliminary Test of Variance. Am. Stat. 1990, 44, 322-326. [CrossRef] 
37. Rascha, D.; Teuscherb, F.; Guiard, V. How robust are tests for two independent samples? J. Stat. Plan. Inference 2007, 137, 2706-2720. [CrossRef]

38. Osborne, J.; Simon, S.; Collins, S. Attitudes towards science: A review of the literature and its implications. Int. J. Sci. Educ. 2003, 25, 1049-1079. [CrossRef]

39. Anderson, R.D. Reforming science teaching: What research says about inquiry. J. Sci. Teach. Educ. 2002, 13, 1-12. [CrossRef]

40. Beier, M.E.; Kim, M.H.; Saterbak, A.; Leautaud, V.; Bishnoi, S.; Gilberto, J.M. The effect of authentic project-based learning on attitudes and career aspirations in STEM. J. Res. Sci. Teach. 2019, 56, 3-23. [CrossRef]

41. Martinéz-Jimenéz, P.; Climent-Bellido, M.S. Learning in chemistry with virtual laboratories. J. Chem. Educ. 2003, 80, 346-352. [CrossRef]

42. Doolittle, P.E. Constructivism and Online Education; Virginia Polytechnic Institute \& State University: Blacksburg, VA, USA, 1999; Available online: https://jgregorymcverry.com/readings/Doolittle\%20-\%201999\% 20-\%20Constructivism\%20and\%20online\%20education.pdf (accessed on 28 November 2020).

43. Fosnot, C.T. Constructivism: A psychological theory of learning. In Constructivism: Theory, Perspectives, and Practice; Teachers College Press: New York, NY, USA, 1996; pp. 8-33.

44. Steffe, L.P.; Gale, J. Constructivism in Education; Lawrence Erlbaum: Hillsdale, MI, USA, 1995; p. 575. ISBN1 0-8058-1095-1 (hardback). ISBN2 0-8058-1096-X (paperback).

45. Schneider, R.M.; Krajcik, J.S.; Marx, R.W.; Soloway, E. Performance of students in project-based science classrooms on a national measure of science achievement. J. Res. Sci. Teach. 2002, 39, 410-422. [CrossRef]

46. Marušič, M.; Sliško, J. Many high-school students don't want to study physics: Active learning experiences can change this negative attitude. Revista Braileira de Ensino de Física 2012, 34, 1-11. [CrossRef]

47. Tseng, K.H.; Chang, C.C.; Lou, S.J.; Chen, W.P. Attitudes towards science, technology, engineering and mathematics (STEM) in project-based learning (PjBL) environment. Int. J. Technol. Des. Educ. 2013, 23, 87-102. [CrossRef]

48. Skalková, J. Obecná Didaktika; Grada Publishing: Prague, Czech Republic, 2007; ISBN 80-247-182-17. (In Czech)

49. Edmunds, J.; Arshavsky, N.; Glennie, E.; Charles, K.; Rice, O. The Relationship Between Project-Based Learning and Rigor in STEM-Focused High Schools. Interdiscip. J. Probl. Based Learn. 2017, 11, 3. [CrossRef]

50. Tangworakitthaworn, P.; Gilbert, L.; Wills, G. Towards a Matching Strategy of Constructivism and Instructionism. In Proceedings of the 19th International Conference on Computers in Education, ICCE 2011, Chiang Mai, Thailand, 28 November-2 December 2011.

51. Tkáč, L. Interactive Remote Experiment in Electronics Education. Ph.D. Thesis, MTF STU, Trnava, Slovakia, 2012; p. 148.

52. Başer, M.; Durmuş, S. The effectiveness of Computer Supported Versus Real Laboratory Inquiry Learning Environments on the Understanding of Direct Current Electricity among Pre-Service Elementary School Teachers. Eurasia J. Math. Sci. Educ. 2010, 6, 47-61. [CrossRef]

53. Thornton, R.K. Using the Results Research in Science Education to Improve Science Learning. Available online: http://citeseerx.ist.psu.edu/viewdoc/summary?doi=10.1.1.114.1832 (accessed on 28 November 2020).

54. Matute, H.; Vadillo, M.A. Assessing e-learning in web labs. In Advanced on Remote Laboratories and E-Learning Experiences; University of Deusto Publicaciones: Bilbao, Spain, 2007; pp. 97-107. ISBN 978-84-9830-662-0.

55. Múller, D.; Erbe, H. Collaborative Remote Laboratories in Engineering Education: Challenges and Visions. In Advanced on Remote Laboratories and E-Learning Experiences; University of Deusto Publicaciones: Bilbao, Spain, 2007; pp. 35-59. ISBN 978-84-9830-662-0.

Publisher's Note: MDPI stays neutral with regard to jurisdictional claims in published maps and institutional affiliations. 